\title{
Properties of concrete having treated recycled coarse aggregate and slag
}

\author{
P. Saravanakumar (Main Author and Corresponding Author)
}

Associate Professor, Department of Civil Engineering, Sri Krishna College of Engineering and Technology, Coimbatore 641008 (India) psaravana2000@gmail.com

https://orcid.org/0000-0002-7963-9784

D. Manoj

Assistant Professor, Department of Civil Engineering, Kamala Institute of Technology and Science, Telangana 505468 (India)

manohbx@gmail.com

https://orcid.org/0000-0003-1721-792x

S. Jagan

Faculty of Civil Engineering, Kalasalingam Academy of Research and Education, Anand Nagar, Krishnankoil 626126 (India)

s.jagan@klu.ac.in

https://orcid.org/0000-0002-4196-7803

Manuscript Code: 15452

Date of Acceptance/Reception: 31.05.2021/17.06.2020

DOI: 10.7764/RDLC.20.2.249

\begin{abstract}
The possibility of using substitute materials for aggregates and cement in concrete were studied and reported in this paper. Concrete mixtures with untreated recycled coarse aggregates (URCA) and treated recycled coarse aggregates (TRCA) were used to prepare two mix groups of without slag (Mix I) and with slag (Mix II). The recycled aggregates were treated with hydrochloric acid $(\mathrm{HCl})$ having different molarities $(0.1 \mathrm{M}, 0.3 \mathrm{M}$ and $0.5 \mathrm{M})$ before used as a substitute material for virgin aggregate in concrete. The concrete mechanical, durability properties and morphology of concrete were examined through standard experiments and analysed. In both mix groups considerable improvement in all characteristics were identified in TRCA mixes than URCA mixes. Among the two mix groups the concrete mix with slag (Mix II) showed better durability characteristics than mix without slag (Mix I). The combination of TRCA and slag in concrete substantially increases the characteristics of concrete in all means.
\end{abstract}

Keywords: treated recycled coarse aggregate, untreated recycled coarse aggregate, slag, $\mathrm{HCl}$, molarity.

The population growth, industrial development and housing needs increase the global aggregate production of the construction industry and it was almost doubled in the last ten years (Tam et al. 2018). Similarly the cement production contributes $8 \%$ of the global anthropogenic greenhouse gas emissions and 3\% of global energy demand (Miller 2020). The increase in global demand for construction materials increases the depletion of natural resources and energy. This becomes a global problem and urges the researchers to find an alternate material and to protect the natural resources and environment. Every year globally more than 2 billion tons of construction and demolition (C\&D) wastes are generated and disposed in landfills, leads to environmental problems (Tam et al. 2018). Recycling and using the construction and demolition wastes (C\&DW) and reducing the cement usage by using alternate mineral admixtures in concrete becomes a vital solution for the above problem. The $\mathrm{ACl} 233 \mathrm{R}-03$ reported that, many countries accepted since from late 1950's the utilization of mineral admixtures like GGBFS as a substitute material in concrete. Globally the applications of C\&D wastes and mineral admixtures like fly ash, GGBFS etc. obtained from industrial wastes were tried by varying the application percentages from $0 \%$ to $100 \%$ in concrete with more combinations like concrete with mineral admixtures, concrete with recycled aggregates, concrete with recycled aggregate and mineral admixtures etc. (Sharma 2017, Sivamani et.al. 2021).

From the earlier reports it was understood that applications of recycled aggregate in concrete result $40 \%$ lesser strength compared to the control concrete. Workability, bonding and durability characteristics also affected significantly while using recycled coarse aggregate (RCA) in concrete. RILEM Technical Committee 121-DRG (1994) report restricted the recycled material replacement for all strength classes of concrete to $20 \%$. The major reason for these negative results of RCA was the presence of loose particles and adhered mortar present on RCA. Using RCA in saturated surface dry state or adding extra water in the concrete positively modified the fresh concrete properties if the aggregate water absorption is greater than $5 \%$ (Taboada et al., 2016). 
An extensive experimental work was done by the Saravanakumar et.al. $(2012 ; 2013 ; 2014 ; 2015)$ and Kou et.al. (2011; 2013) with RCA and mineral admixtures like fly ash, GGBFS, SF and metakaolin applications in concrete. They reported that using recycled aggregates in combination with mineral admixtures gave satisfactory results on both mechanical and durability characteristics. Specifically the SF and metakaolin enhanced the mechanical and the durability properties and Flyash and GGBFS enhanced the durability characteristics. Number of previous studies (Revathi et al., 2015; Tam et al., 2007; Sallehan and Mahyuddin, 2013; Ryou and Lee, 2014; Saravanakumar et al., 2016) concluding that surface treatment methods like acid presoaking method and surface impregnation can be successfully used to mitigate the poor performance of the RCA. Tam et al., 2007 reported that by presoaking the RCA in acidic environment (Hydrochloric acid $(\mathrm{HCl}))$ changed the recycled aggregate surface by significantly removed the existing adhered mortar and improve the RCA characteristics.

They also reported that RCA treated with $\mathrm{HCl}$ acid of low molarities (up to $0.5 \mathrm{M}$ ) resulted to better characteristic strength than high molarity acid treated concrete. Revathi et al., 2015 concluded that, $\mathrm{H} 2 \mathrm{SO} 4$ acid presoaking treatment was very effective and removed more adhered mortar than the $\mathrm{HCl}$ acid presoaking treatment and also the quality of $\mathrm{H} 2 \mathrm{SO} 4$ treated RCA was on par with natural coarse aggregpate. Regarding surface impregnation treatment method Sallehan and Mahyuddin 2013 compared the calcium metasilicate solution treated and nano silica treated RCA and reported that the concrete with $10 \%$ concentrated calcium metasilicate solution treated RCA results better strength characteristics than nano silica treated RCA. Ryou and Lee, 2014 reported that the concrete characteristics was significantly improved when using water-soluble polycarboxylate dispersant surface coated RCA in concrete. Saravanakumar et al., 2016 concluded from their study that the acid treated recycled aggregates further impregnated with silica fume result better densified recycled aggregate and improve the strength and durability properties. Ong et al. 2010 studied the microwave treated recycled aggregate replacement level and reported that the increase in percentage addition of recycled aggregates reduced the strength of the concrete but not significant upto the replacement level of $40 \%$.

From the literature study, it was understood that the acid $(\mathrm{HCl})$ treatment improve the strength of the URCA and presence of GGBFS in concrete improved the durability of concrete. In this study to enhance the properties of the aggregate and also the durability of concrete, combination of both treated aggregates and partial replacement of cement with GGBFS was tried and comparison was also done with URCA concrete.

Experimental investigations

\section{Materials}

Type 1 Cement confirming to ASTM C150 standard was used throughout this study. Commercially available GGBFS were used as partial replacement material for cement. The chemical composition of cement and GGBFS (Table 1) were satisfied the ASTM C150 and ACl 233R-03 requirements respectively. To cast control mix virgin aggregates available in local quarry satisfied the standards of size 12 - $16 \mathrm{~mm}$ were used. Recycled coarse aggregates (URCA) were retrieved from the demolished reinforced concrete beams having $25 \mathrm{MPa}$ compressive strength (verified with rebound hammer test) of 50 Years old building. The concrete was separated from reinforced beams, crushed through a jaw crusher, sieved to fractions ranging from 12-16 mm size and cleaned with water washing to remove loose particles. The standard of recycled aggregates used throughout this study were verified and found as Group II RCA as per RILEM standard.

\begin{tabular}{lccccccc}
\multicolumn{7}{c}{ Table 1. Chemical composition of cementitious materials used. (Self - Elaboration). } \\
\hline Description & $\mathrm{SiO}_{2}$ & $\mathrm{Al}_{2} \mathrm{O}_{3}$ & $\mathrm{CaO}$ & $\mathrm{Fe}_{2} \mathrm{O}_{3}$ & $\mathrm{Na}_{2} \mathrm{O}$ & $\mathrm{MgO}$ & $\mathrm{K}_{2} \mathrm{O}$ \\
\hline Cement & 24.50 & 7.00 & 63.00 & 0.55 & 0.40 & 2.00 & 0.60 \\
$\begin{array}{l}(\%) \\
\text { GGBFS (\%) }\end{array}$ & 34.01 & 16.62 & 34.85 & 1.71 & 0.48 & 9.11 & 0.46 \\
\hline
\end{tabular}

\section{Acid treatment for recycled aggregates}

The retrieved and crushed RCA were treated by immersed it in three different molarities of hydrochloric acid (0.1M, $0.3 \mathrm{M}$ and $0.5 \mathrm{M})$ in room temperature $\left(27^{\circ} \mathrm{C}\right.$ to $\left.30^{\circ} \mathrm{C}\right)$ for 24 hours. The acid treatment procedure used in this study followed Tam et.al. 2007. Using distilled water the presoaked aggregates were completely cleaned and left to dry in sunlight for one day and after that it was sieved. In this process the loose mortars and acidic solvents were removed. 


\section{Mix proportions}

The mix ratio of 1:1.47:2.38 with water to binder ratio of 0.40 as per ACl method to achieve 30MPa concrete was used in this study. The medium workable slump range of $50 \mathrm{~mm}$ to $90 \mathrm{~mm}$ as per ASTM C143 standard was chosed for this study. To obtain the uniform workability for all concrete mixtures, Naphthalene Sulphonate based super plasticizer of maximum $2 \%$ by mass of cement content and saturated surface dry (SSD) aggregates were used in concrete. The purpose of using SSD aggregates in concrete was to avoid water loss due to absorption of adhered mortar in RCA during mixing, concreting and hardening. Two sets of mix groups (Mix I -without GGBFS and Mix II - partial replacement of cement with $25 \%$ GGBFS) were prepared with untreated recycled aggregates and $0.1 \mathrm{M}, 0.3 \mathrm{M}$ and $0.5 \mathrm{M} \mathrm{HCL}$ treated recycled aggregates by replacing natural coarse aggregate (NA) with $100 \%$ recycled coarse aggregates (RA). The mix proportions and the concrete material quantities were tabulated in Table 2.

Table 2. Mix proportions. (Self - Elaboration).

\begin{tabular}{|c|c|c|c|c|c|c|c|c|c|c|}
\hline \multirow[t]{2}{*}{ Materials } & \multicolumn{5}{|c|}{$\operatorname{Mix} I\left(\mathrm{~kg} / \mathrm{m}^{3}\right)$} & \multicolumn{5}{|c|}{$\operatorname{Mix} I I\left(\mathrm{~kg} / \mathrm{m}^{3}\right)$} \\
\hline & $\mathrm{CC}$ & URAC & TRAC $_{0.1 \mathrm{M}}$ & TRAC $_{0.3 \mathrm{M}}$ & TRAC $_{0.5 \mathrm{M}}$ & SC & SURAC & STRAC & STRAC & STRAC \\
\hline & & & & & & & & $0.1 \mathrm{M}$ & $0.3 \mathrm{M}$ & $0.5 \mathrm{M}$ \\
\hline Cement & 476 & 476 & 476 & 476 & 476 & 357 & 357 & 357 & 357 & 357 \\
\hline GGBFS & 0 & 0 & 0 & 0 & 0 & 119 & 119 & 119 & 119 & 119 \\
\hline Fine Aggregate & 701 & 701 & 701 & 701 & 701 & 701 & 701 & 701 & 701 & 701 \\
\hline NA & 1135 & & & & & 1135 & & & & \\
\hline URCA & & 1135 & & & & & 1135 & & & \\
\hline $\mathrm{RAC}_{0.1 \mathrm{M}}$ & & & 1135 & & & & & 1135 & & \\
\hline $\mathrm{RAC}_{0.3 \mathrm{M}}$ & & & & 1135 & & & & & 1135 & \\
\hline $\mathrm{RAC}_{0.5 \mathrm{M}}$ & & & & & 1135 & & & & & 1135 \\
\hline
\end{tabular}

\section{Experiments and specimen details}

To find the fresh concrete properties and strength of the concrete, slump cone test, compressive and split tensile strength tests were conducted as per BS EN 12350-2, BS1881 and ASTM C496 standards respectively. Cubes of size 150 $\mathrm{mm}$ and cylinders of size $150 \mathrm{~mm} \times 300 \mathrm{~mm}$ (diameter $\mathrm{x}$ height) were cast and tested for compressive and tensile strength respectively for 7,28 , and 90 days to study the effect of age of concrete. The average values of 3 specimens were taken to assess the specimen characteristics for all ages in each mix series. Concrete specimens were well compacted with the help of a table vibrator. The specimens were cured up to the testing period of 90 days in curing tank. The durability characteristics such as alkalinity, sorptivity, and resistance against chloride penetration were also studied as per ASTM standards ASTM C1585 and ASTM C1202. Cube specimens of size $100 \mathrm{~mm}$ and cylinders of size 100 $\mathrm{mm} \times 50 \mathrm{~mm}$ (diameter $\mathrm{x}$ height) were cast and tested for the above durability tests.

\section{Results and discussions}

\section{Aggregate properties}

From the earlier study (Saravanakumar et. al. 2012) it was understood that the physical properties of the recycled aggregates are inferior to the virgin aggregates. This was because of the mortar adhered on the recycled aggregate. In this study similar observations were found in the experimental results. The density of aggregate before treatment was only $83 \%$ of natural aggregate. After treatment it went upto $93 \%$. Similarly the water absorption for untreated recycled aggregates was very high (6.5\%) initially, but after treatment it got reduced and reached 3.5\% which was very close to natural aggregate absorption. Improved characteristics were found in the treated recycled aggregates than the recycled aggregate due to the elimination of mortar content from the recycled aggregate after treatment. Up to $0.5 \mathrm{M} \mathrm{HCl}$ treatment no adverse effect on recycled aggregate properties were observed. The adhered mortar removal was more when the concentration of $\mathrm{HCl}$ increases.

The physical and mechanical properties of URCA and RCA were shown in the Table 3. When the RCA were immersed in $\mathrm{HCl}$, it reacts with the existing adhered mortar and form gypsum and ettringite. Initially these reaction products occupy the voids in the adhered mortar and increase the weight of the aggregate. Finally the continued expansion of adhered 
mortar leads to peeling off of the surface layer of adhered mortar. The results from the earlier study by Revathi et al. 2015 also confirmed that considerable amount of mortar content was removed by the acid soaking treatment and the properties of recycled aggregates were improved after treatment.

\begin{tabular}{llllll}
\multicolumn{7}{c}{ Table 3. Properties of coarse aggregates. (Self - Elaboration). } \\
\hline Property & NCA & URCA & RCA $0.1 \mathrm{M}$ & RCA $_{0.3 \mathrm{M}}$ & RCA $_{0.5 \mathrm{M}}$ \\
\hline Specific gravity & 2.70 & 2.47 & 2.53 & 2.58 & 2.62 \\
Density $\left(\mathrm{kg} / \mathrm{m}^{3}\right.$ ) & 1675 & 1393 & 1450 & 1481 & 1551 \\
Impact value (\%) & 5.8 & 25.41 & 23.53 & 21.92 & 20.51 \\
Crushing (\%) & 17.7 & 32.74 & 30.46 & 28.32 & 26.50 \\
Water absorption (\%) & 3 & 6.48 & 4.4 & 3.7 & 3.5 \\
\hline
\end{tabular}

\section{Fresh concrete properties}

The workability of the concrete was examined through slump cone test and the results are reported in Figure 1 . The experimental results indicated that the RCA substitution significantly affect the workability of the concrete. The $100 \%$ untreated recycled aggregate concrete resulted very stiff concrete having a slump of $33 \mathrm{~mm}$. The higher water absorption of RCA leads to poor workability. Using treated recycled aggregate in concrete showed better workability and for TRAC $0.5 \mathrm{M}$ attained $90 \%$ of the slump value of control concrete. For control concrete the partial replacement (25\%) of cement with GGBFS didn't showed any difference in the workability (Slump $55 \mathrm{~mm}$ ) whereas, slight improvement in workability was found in recycled aggregate concrete. The relatively smooth glassy surface texture of the GGBS particles compared to the rough texture of Portland cement particles improved the workability of recycled aggregate concrete.

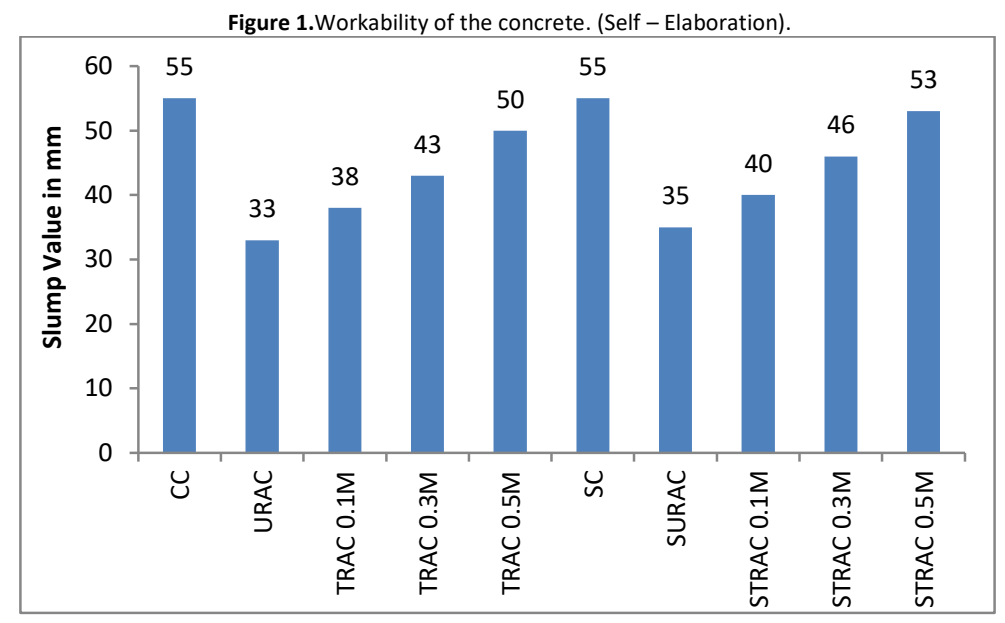

\section{Hardened concrete properties}

\section{Compressive strength properties}

The compressive strength values of two mix groups of without slag and with slag comprising ten concrete mixes were found at the different curing age of 7,28 and 90 days. From the experimental results shown in Figure 2, it was understood that the characteristic compressive strength of concrete was severely affected by the replacement of natural coarse aggregate with recycled coarse aggregate. The earlier reports also confirmed that the source of the RCA also affects the compressive strength of RAC (Hansen and Narud, 1983). In this study the RCA obtained from a single source was used and the strength was found as $25 \mathrm{MPa}$ before demolition. When compare to the control concrete the untreated RAC attained $72 \%$ and $73 \%$ compressive strength at the age of 28 days and 90 days respectively. Similar trend was found in many earlier research reports and this decreasing strength was because of the existing mortar present in the RCA (Li et al., 2009). To improve the strength of RAC the existing mortar was removed from the recycled aggregates used for concrete mix preparation through presoaking the RCA in $\mathrm{HCl}$ acid of different molarities. The TRAC $0.1 \mathrm{M}, \mathrm{TRAC}_{0.3}$ $\mathrm{M}, \mathrm{TRAC}_{0.5} \mathrm{M}$ concrete mixes attained $73 \%, 77 \%$ and $81 \%$ strength of control concrete respectively at the age of 28 days and $75 \%, 78 \%$ and $83 \%$ strength of control concrete respectively at the age of 90 days. From the results it was observed that regardless of the age the $0.5 \mathrm{M} \mathrm{HCl}$ treated better performance. It indicates that the aggregate characteristics of the $0.5 \mathrm{M}$ treated were significantly improved than other molarity treated aggregates. The partial (25\%) replacement of cement with GGBFS also affects the strength of the concrete in the earlier age but the strength gain was found improved when it was tested after 28 days curing. The GGBFS admixed control concrete attained $89 \%$ strength of control 
concrete at the age of 7 days and it attained $99.5 \%$ strength at the age of 90 days. Similar trend was found in RAC also. The STRAC $0.1 \mathrm{M}$, STRAC $_{0.3 \mathrm{M}}$, STRAC $0.5 \mathrm{~m}$ concretes attained $71 \% 74 \%$ and $80 \%$ strength respectively at the age of 28 days and $75 \%, 78 \%$ and $84 \%$ strength at the age of 90 days. In slag concrete the rate of strength gain was higher in the later age. In RAC the GGBFS present in the recycled aggregate pores reacts in the later age and produce more gel thereby improve the rate of strength gain (Kou et al., 2011; Saravanakumar and Dhinakaran, 2015).

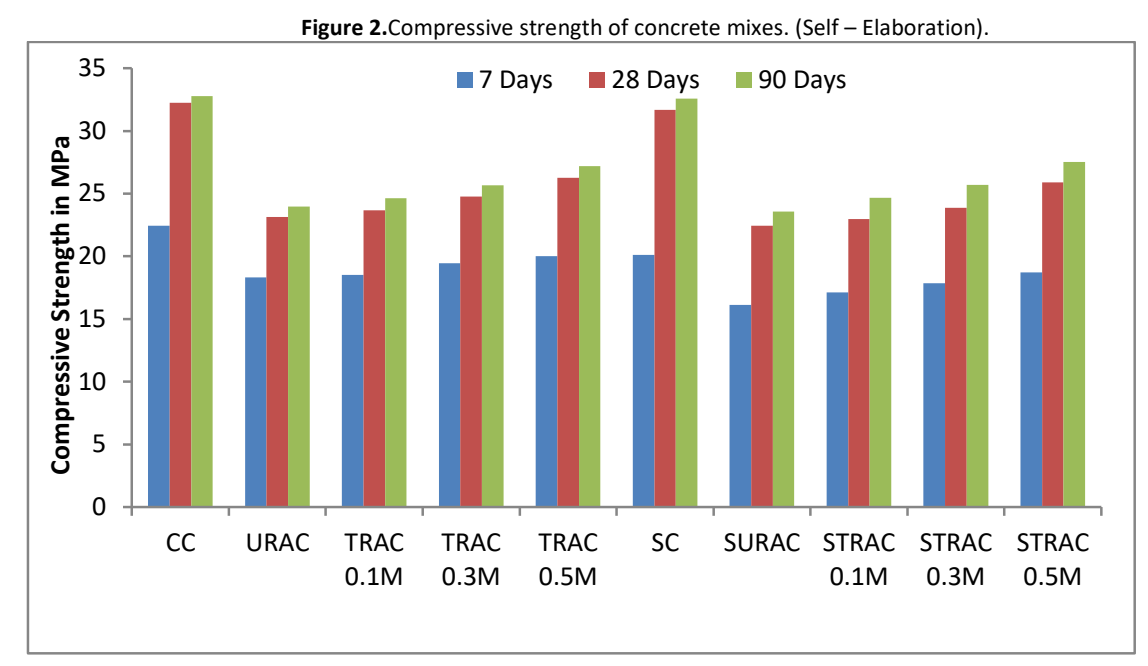

\section{Tensile strength properties}

The split tensile strength of both two concrete mix groups was shown in Figure 3. The split tensile strength test results showed the similar trend as compressive strength. From the experimental results it was understood that $100 \%$ utilization of RCA in concrete reduces the tensile strength of URAC concrete to the extent of $22 \%$. Similar trend was reported in many earlier research reports also (Yu-chang et al., 2015; Padmini et al., 2009). Researchers tried in many ways to reduce this negative effect of using RCA in concrete by adding admixtures and by using treated RCA in concrete. In this study from the experimental results significant improvement in the tensile strength was found when treated RCA and GGBFS were used in concrete. In first mix group (RAC without GGBFS), at the age of 28 days the untreated RAC attained $77 \%$ of the control concrete strength and the concrete with treated RCA attained up to $87 \%$ strength of control concrete. Among the three $(0.1 \mathrm{M}, 0.3 \mathrm{M}$ and $0.5 \mathrm{M} \mathrm{HCl})$ acid treatment, maximum tensile strength increment of $13 \%$ was noticed in $0.5 \mathrm{M} \mathrm{HCl}$ treated RAC than untreated RAC. In the second mix group ( $25 \%$ of cement was replaced with GGBFS) the rate of strength gain at the later age was higher than the earlier age. In control concrete at the age of 28 days $2 \%$ lesser tensile strength was observed in GGBFS concrete but at the later age (90 days) $1 \%$ higher tensile strength was noticed. In RAC the tensile strength difference between the mix group 1 and II at the age of 28 and 90 days were $7.25 \%$ and $3.7 \%$ respectively.

The same trend was noticed in treated RAC also. From the experimental results it was observed that GGBFS based RAC with $0.5 \mathrm{M} \mathrm{HCl}$ treated RCA attained a maximum of $84 \%$ control concrete tensile strength which was $10 \%$ higher than RAC with untreated RCA. Since GGBFS were much finer than cement, in GGBFS based recycled aggregate concrete the presence of GGBFS in the concrete filled the micro pores which enhanced the pozzolanic action reacts in the later age and produce more gel and thereby improve the rate of strength gain at the later age. Because of this the GGBFS based recycled aggregate concrete exhibits better strength gain in the later age. 


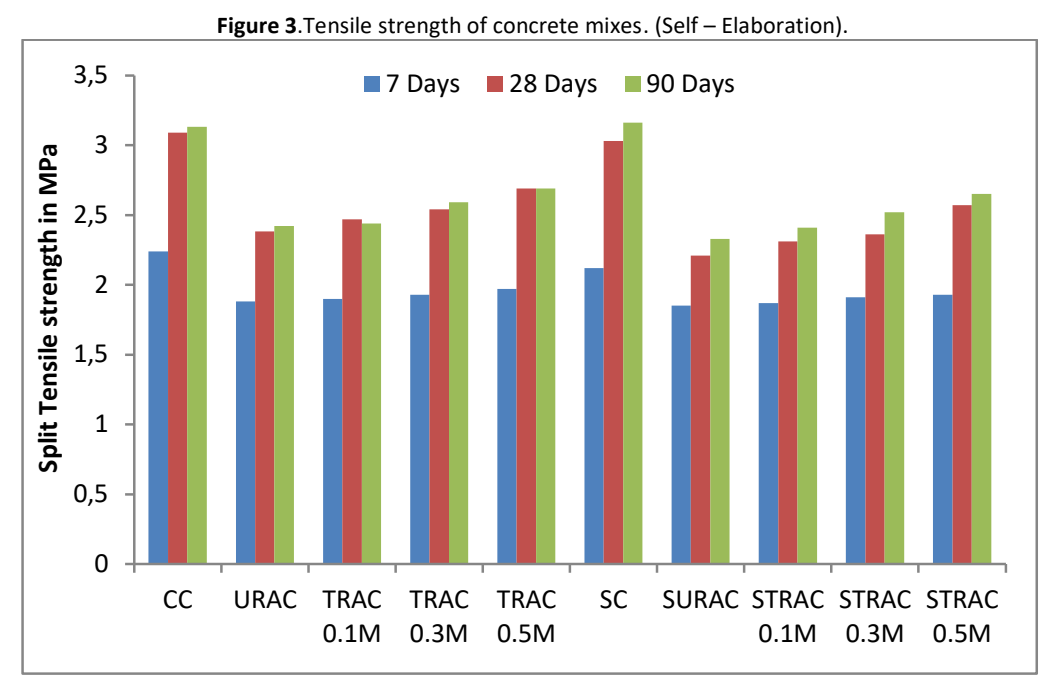

\section{Durability properties}

\section{Alkalinity}

The concrete degradation level was measured through the alkalinity test. The measure of pH indicates the deteriorated condition of the concrete. The good conditioned concrete exhibits the $\mathrm{pH}$ value of 12 to 13 . Up to the $\mathrm{pH}$ value of 9 was permitted (Deschner et al. 2016). Below the $\mathrm{pH}$ value of 9 represented the severe degradation of the concrete structure. Decrease in $\mathrm{pH}$ induces chloride attack and spalling of concrete as concrete is highly alkaline material. As the $\mathrm{pH}$ is lowered, the bonding capability of cement gets lowered and the corrosion gets initiated (Deschner et al. 2016).

The $\mathrm{pH}$ value for the different RAC mixtures were found from the 28 days strength tested concrete samples and the results were presented in the Figure 4 . Since all the concrete mixtures presented in Figure 4 have the $\mathrm{pH}$ range of 11 to 13 it was concluded that the possibility of corrosion was low. The corrosion resistance of RAC was lesser than the control concrete and using treated recycled aggregates the corrosion resistance increases. The concrete containing GGBFS showed better resistance against corrosion irrespective of all concrete mixes. Among all RAC mixes higher resistance was found in concrete containing $0.5 \mathrm{M} \mathrm{HCl}$ treated RCA and $25 \%$ GGBFS. The slag in the concrete contains high amounts of alumina and amorphous silica which improves the filler effect and pozzolanic reaction.

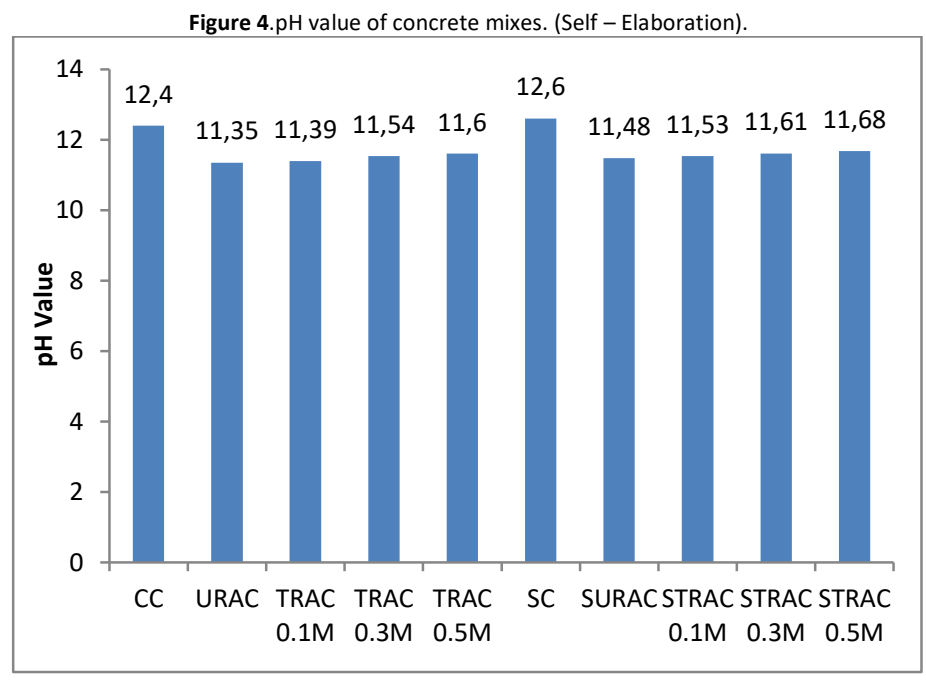

\section{Sorptivity}

The rate of capillary suction of hardened concrete reflects the micro structural properties of hardened concrete's capacity (Zhang et al. 2014, Jalilifar et al. 2020). The absorption rate was computed for both mix groups and it was shown in Figure 5(a), Figure 5(b) and Figure 6. The initial 6 hours readings were plotted and the slope of the best fit line having r2 values not less than 0.98 were drawn to compute the sorptivity value for all concrete mixtures. Irrespective of the mix group the rate of water absorption was increased with the square root of time. From the experimental results, it 
was clear that the sorptivity was higher for the untreated RCA concrete specimens than treated RCA concrete specimens. This may be due to the high porous nature due to existing adhered mortar of untreated RCA even after cleaning.

With respect to control concrete the sorptivity value for the untreated RCA was greater than the double. But when the treated RCA was used in the concrete the absorption of RAC was reduced and there by the sorptivity value was also reduced. When the aggregates were treated with $0.5 \mathrm{M} \mathrm{HCl}$, significant improvement in sorptivity value was observed than all the other treated RCA concrete specimens. This was further improved when the treated recycled aggregates and partial replacement of cement with slag were used in the concrete. From the experimental results it was understood that $10 \%$ reduction in sorptivity value found in slag concrete with respect to control concrete. In SURAC concrete $7 \%$ reduction was found with respect to URAC concrete.

Upto $24 \%$ reduction in sorptivity was observed in STRAC concrete. This may be because of two reasons. The first one was the removal of loose and adhered mortar on the RCA due to acid treatment. The second reason may be the alteration of soluble excess lime to cementitious compounds and the possibility of formation of more amount of $\mathrm{C}$-S-H gel when slag concrete hydrate (Chen et al. 2004). These lead to the adsorption of more chloride ions, which reduce the void spaces in the concrete. Thereby the permeability was decreased and the bonding characteristics between the paste and the aggregate were improved. The smallest pores in the concrete were filled with finely divided particles of slag, which act like micro-aggregates.
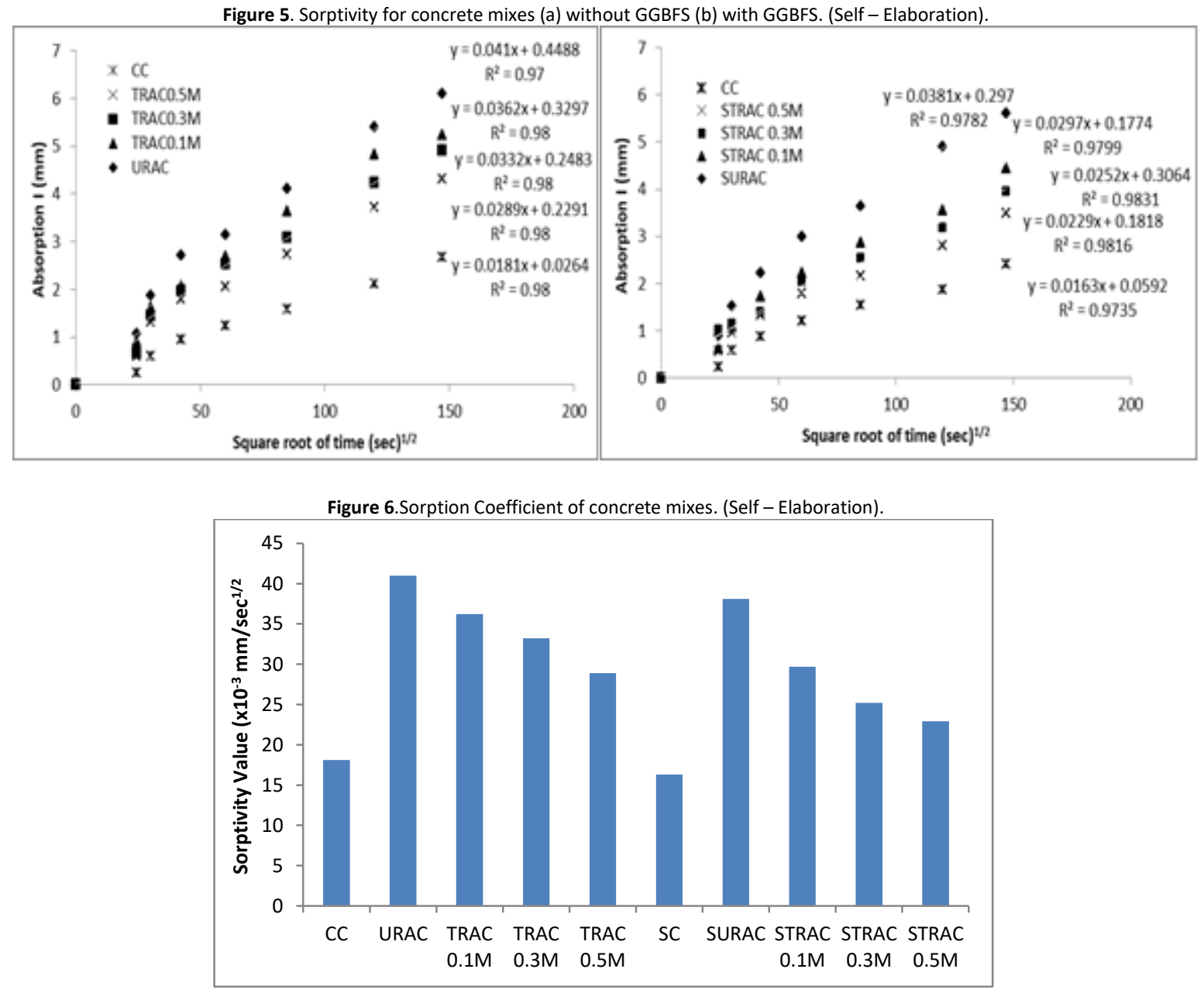

\section{Chloride ion penetration}

The rapid chloride penetration test (RCPT) was conducted and the total charge passed (in Coulombs) through the concrete cylinder specimens were observed as shown in Figure 7. The estimated chloride ion penetration values in coulombs were given in Figure 8. The experimental results indicated that when NCA was replaced with RCA the rate of chloride ingress also increased. This was because of the higher chloride ion absorption due to the porous nature of the adhered mortar of RCA. The permeability of concrete affects the chloride ion penetration of the concrete. The use of treated RCA in concrete reverses the increasing trend and $0.5 \mathrm{M} \mathrm{HCl}$ treated RCA concrete showed higher resistance 
than other concrete specimens. This was because of higher removal of adhered mortar found in $0.5 \mathrm{M} \mathrm{HCl}$ treated RCA than other. However the chloride ion penetration range of URCA and TRCA concrete were in between 3207 to 3420 Coulombs (moderate range). These results encourage the usage of RCA in concrete. The experimental results of GGBFS based treated RCA concrete showed a significant improvement in resistance against chloride ingress in concrete. The total charge passed for CC concrete and SC concrete were 3120 and 3087 coulombs respectively and for GGBFS based concretes containing untreated and treated RCA concrete mixes were in between 3156 to 3367 Coulombs. As per AASHTO T277 rating all concrete mixtures falls in the moderate range. More Calcium-Silicate-Hydrate gel was produced in RCA concrete containing GGBFS during hydration. This gel fills the pores in the RCA concrete and blocks the diffusing path of the concrete. The earlier study also concluded that the chloride ingress in concrete was effectively prevented by using GGBFS in concrete (Elahi et al., 2010; Saravanakumar et al., 2016). The experimental study indicates that the chloride ion movement in TRCA concrete with GGBFS is very slow.

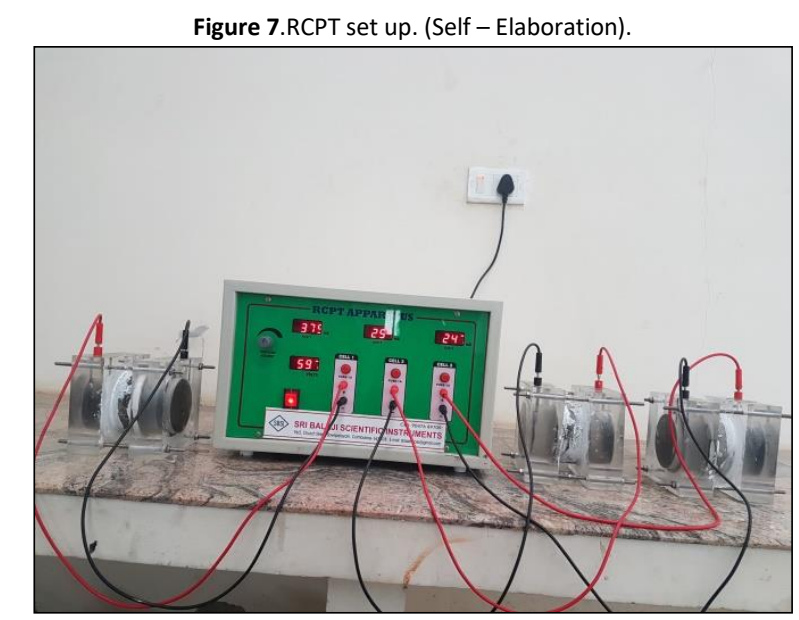

Figure 8.Effect of slag addition on Chloride Ion Penetration of concrete mixes. (Self - Elaboration).

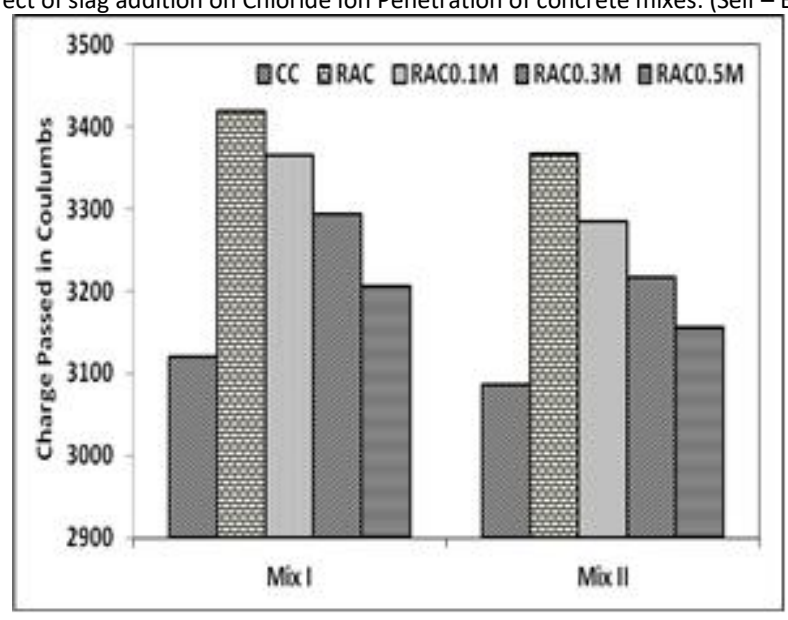

The detailed study on strength and durability characteristics of TRCA and GGBFS on concrete was done and the following conclusions were made:

- Considerable amount of mortar content was removed by the $\mathrm{HCl}$ acid soaking treatment and hence significant improvement of TRCA was noticed on its properties.

- Replacement of virgin aggregate with URCA in concrete significantly affects the workability of the concrete because of the higher water absorption of adhered mortar in recycled aggregate. Smooth glassy surface texture of the GGBS particles and significant reduction in water absorption of TRCA improved the workability of concrete.

- When $100 \%$ recycled aggregate replacement made in concrete the strength attained was $72 \%$ and it was improved to a maximum of $82 \%$ when using TRCA aggregates. Further improvement was noticed at the age of 90 days when $25 \%$ slag and TRCA were used in concrete. 
- The alkalinity of the recycled aggregate concrete was not affected even the RCA was treated with $0.5 \mathrm{M} \mathrm{HCl}$ acid and the concrete containing GGBFS showed better resistance against corrosion.

- The capillary suction rate of RAC was higher than NAC. The sorption resistance was improved by using TRCA and GGBFS in concrete. Higher resistance was observed in $0.5 \mathrm{M} \mathrm{HCl}$ treated RCA and $25 \% \mathrm{GGBFS}$ concrete mixture.

- The rate of chloride ion movement in TRCA concrete with GGBFS is very slow.

- Overall $0.5 \mathrm{M} \mathrm{HCl}$ treated recycled aggregates with $25 \%$ GGBFS concrete mix exhibits better strength and durability characteristics and it can be very well implemented in the construction site.

\section{Acknowledgement}

The authors wish to express their gratefulness to the management of Sri Krishna Institutions, Coimbatore for their support and encouragement given throughout this research work.

On behalf of all authors, the corresponding author states that there is no conflict of interest.

AASHTO T277-86. 1990. Rapid determination of the chloride permeability of concrete, American Association of States Highway and Transportation Officials, Standard Specifications - Part II Tests, Washington, D. C.

$\mathrm{ACl}$ Committee 233. 2003. "Ground granulated blast-furnace slag as a cementitious constituent in concrete", ACl 233 R-03, American Concrete Institute, Farmington Hills, MI, USA.

ASTM C143 / C143M-20, Standard test method for slump of hydraulic-cement concrete, ASTM International, West Conshohocken, PA, 2020, www.astm.org

ASTM C150/C150M-16e1. 2020. Standard specification for portland cement, ASTM International, West Conshohocken, PA.

ASTM C496/496-M-11. 2020. Standard test method for splitting tensile strength of cylindrical concrete specimens, ASTM International, West Conshohocken, PA.

ASTM C1585. 2011. Standard test method for measurement of rate of absorption of water by hydraulic-cement concretes. ASTM International, West Conshohocken, PA.

ASTM C1202. 2015. Standard test method for electrical indication of concrete's ability to resist chloride ion penetration. ASTM International, West Conshohocken, PA.

BS1881-116 1983. Testing concrete. Method for determination of compressive strength of concrete cubes, British Standard Institution, London.

BS EN 12350-1:2019. Testing fresh concrete. Sampling and common apparatus, British Standard Institution, London.

Chen, J., Thomas, J., Taylor, H., \& Jennings, H. (2004). Solubility and structure of calcium silicate hydrate. Cement and Concrete Research, 34(9), 14991519 .

Deschner, F., Winnefeld, B., Lothenbach, S., Seufert, P., Schwesig, S., Dittrich, F., Goetz-Neunhoeffer, J., \& Neubauer. (2012). Hydration of portland cement with high replacement by siliceous fly ash. Cement and Concrete Research, 42, 1389-1400.

Elahi, A., Basheer, P. A. M., Nanukuttan, S. V., \& Khan, Q. U. Z. (2010). Mechanical and durability properties of high performance concrete containing supplementary cementitious materials. Construction and Building Materials, 24(3), 292-299.

Hansen, T. C., \& Narud, H. (1983). Strength of recycled concrete made from crushed concrete coarse aggregate. Concrete International: Design and Construction, 5(1): 79-83.

Jalilifar, H., Sajedi, F., \& Toosi, V. R. (2020). Evaluating the durability of recycled concrete made of coarse recycled aggregate concrete containing silicafume and natural zeolite. Revista de la Construcción. Journal of Construction, 19(3), 457-473.

Kou, S. C., Poon, C. S., \& Agrela, F. (2011). Comparisons of natural and recycled aggregate concretes prepared with the addition of different mineral admixtures. Cement and Concrete Composites, 33, 788-795.

Kou S. C, \& Poon C. S. (2013). Long-term mechanical and durability properties of recycled aggregate concrete prepared with the incorporation of fly ash. Cement and Concrete Composites, 37, 12-19.

Li, J. S., Xiao, H. N., \& Zhou, Y. (2009). Influence of coating recycled aggregate surface with pozzolanic powder on properties of recycled aggregate concrete. Construction and Building Materials, 23(3), 1287-1291.

Miller, S.A., \& Moore, F.C. (2020). Climate and health damages from global concrete production. Nature Climate Change, 10, 439-443. 
Ong K. C. G., Ali A., Zhang M. H., Tam C. T., Hao J., \& Timothy W. J. F. (2010). Mechanical properties of concrete incorporating microwave-treated recycled concrete aggregates. In proceedings of the 35th Conference on Our World in Concrete \& Structure, Singapore. Article Online Id: 100035004.

Padmini, A. K., Ramamurthy, K., \& Mathews, M. S. (2009). Influence of parent concrete on the properties of recycled aggregate concrete. Construction and Building Materials, 23(2), 829-836.

Revathi P., Ramesh R., Amirthavalli \& Lavanya K. (2015). Influence of Treatment Methods on the Strength and Performance Characteristics of Recycled Aggregate Concrete. Journal of Materials in Civil Engineering, 27(5), 04014168.

RILEM TC 121 DRG. (1994). Recommendation: specification for concrete with recycled aggregates. Materials and Structures, 27(173), 557-559.

Ryou, J. S., \& Lee, Y. S., (2014). Characterization of Recycled Coarse Aggregate (RCA) via a Surface Coating Method. International Journal of Concrete Structures and Materials, 8(2), 165-172.

Sallehan, I., \& Mahyuddin, R. (2013). Engineering properties of treated recycled concrete aggregate (RCA) for structural applications. Construction and Building Materials, 44, 464-476.

Saravanakumar, P., \& Dhinakaran, G. (2012). Effect of admixed recycled aggregate concrete on properties of fresh and hardened concrete. Journal of Materials in Civil Engineering, 24(4), $494-498$.

Saravanakumar, P., \& Dhinakaran, G. (2013). Strength characteristics of high-volume fly ash-based recycled aggregate concrete. Journal of Materials in Civil Engineering, 25(8), $1127-1133$.

Saravanakumar, P., Dhinakaran, G., \& Marimuthu, K. (2014). Performance of Sustainable Concrete containing HVFA and RCA. Asian Journal of Applied Sciences, 7(4), $194-204$.

Saravanakumar, P., and Dhinakaran, G. (2015). Mechanical and Durability properties of slag based recycled aggregate concrete. IJST, Transactions of Civil Engineering, 39(C2), 271-282.

Saravanakumar, P., Abhiram, K., \& Manoj, B. (2016). Properties of treated recycled aggregates and its influence on concrete strength characteristics. Construction and Building Materials, 111, 611-617.

Sharma, R. (2017). Laboratory Study on Effect of Construction Wastes and Admixtures on Compressive Strength of Concrete. Arabian Journal for Science and Engineering, 42, $3945-3962$.

Sivamani J., Neelakantan T.R., Saravana Kumar P., Mugesh Kanna C., Vignesh Harish H., \& Akash M.R. (2021). Efficient Utilization of Recycled Concrete Aggregates for Structural Applications-An Experimental Study. Lecture Notes in Civil Engineering, 97, Springer, Cham.

Taboada, G. I., Fonteboa, G. B., Abella, M. F., \& Lopez, C. D. (2016). Study of recycled concrete aggregate quality and its relationship with recycled concrete compressive strength using database analysis. Materiales de Construcción, 66(323), 10.3989/mc.2016.06415.

Tam, V. W. Y., Tam, C. M., \& Le, K. N. (2007). Removal of cement mortar remains from recycled aggregate using pre-soaking approaches. Resources, Conservation and Recycling, 50(1), 82-101

Tam, V. W. Y., Soomro, M., \& Evangelista, A. C. J. (2018). A review of recycled aggregate in concrete applications (2000-2017). Construction and Building Materials, 172, 272-292.

Yu-chang, L., Zheng-mao, Y., Franck, V., \& Yunping, Xi. (2015). Development of Processing Methods to Improve Strength of Concrete with 100\% Recycled Coarse Aggregate. Journal of Materials in Civil Engineering, 27(5), 04014163.

Zhang, S. P., \& Zong, L. (2014). Evaluation of Relationship between Water Absorption and Durability of Concrete Materials. Advances in Materials Science and Engineering, 2014: Article ID 650373, https://doi.org/10.1155/2014/650373 